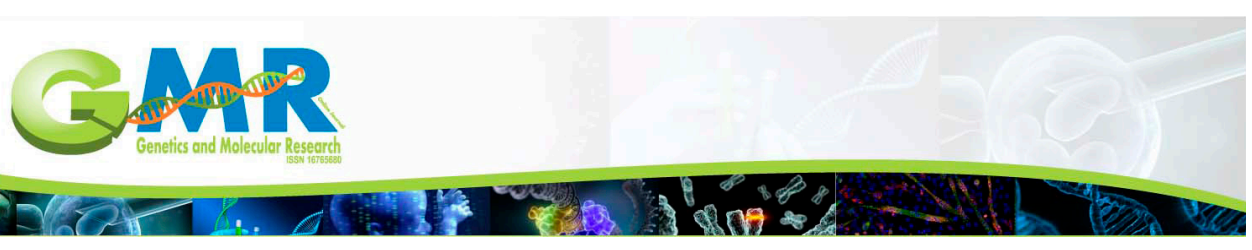

\title{
A rare case of a boy with de novo microduplication at 5q35.2q35.3 from central Brazil
}

\author{
F.G. Reis ${ }^{1,4}$, I.P. Pinto ${ }^{2,4}$, L.B. Minasi ${ }^{3,4}$, A.V. Melo ${ }^{2,4}$, D.M. da C. Cunha ${ }^{4}$, \\ C.L. Ribeiro ${ }^{2,4}$, C.C. da Silva $a^{2,3,4,5}$, D. de M. Silva ${ }^{1,3}$ and A.D. da Cruz ${ }^{2,3,4,5}$ \\ ${ }^{1}$ Programa de Pós-Graduação em Genética e Biologia Molecular, \\ Instituto de Ciências Biológicas, Universidade Federal de Goiás, Goiânia, \\ GO, Brasil \\ ${ }^{2}$ Programa de Pós-Graduação em Biotecnologia e Biodiversidade, \\ Rede Centro Oeste de Pós-Graduação, Pesquisa e Inovação, \\ Universidade Federal de Goiás, Goiânia, GO, Brasil \\ ${ }^{3}$ Programa de Pós-Graduação Mestrado em Genética, Departamento de Biologia, \\ Pontifícia Universidade Católica de Goiás, Goiânia, GO, Brasil \\ ${ }^{4}$ Núcleo de Pesquisas Replicon, Departamento de Biologia, \\ Pontifícia Universidade Católica de Goiás, Goiânia, GO, Brasil \\ ${ }^{5}$ Laboratório de Citogenética Humana e Genética Molecular, \\ Secretaria de Estado da Saúde de Goiás, \\ Laboratório de Saúde Pública Dr. Giovanni Cysneiros (LAGENE/LACEN/ \\ SESGO), Goiânia, GO, Brasil \\ Corresponding author: F.G. Reis \\ E-mail: fafireis28620@gmail.com
}

Genet. Mol. Res. 16 (1): gmr16019197

Received September 6, 2016

Accepted November 17, 2016

Published January 23, 2017

DOI http://dx.doi.org/10.4238/gmr16019197

Copyright $(2017$ The Authors. This is an open-access article distributed under the terms of the Creative Commons Attribution ShareAlike (CC BY-SA) 4.0 License.

ABSTRACT. Genomic disorders are genetic diseases that are caused by rearrangements of chromosomal material via deletions, duplications, and inversions of unique genomic segments at specific

Genetics and Molecular Research 16 (1): gmr16019197 
regions. Such rearrangements could result from recurrent non-allelic homologous recombination between low copy repeats. In cases where the breakpoints flank the low copy repeats, deletion of chromosomal segments is often followed by reciprocal duplication. Variations in genomic copy number manifest differently, with duplication and deletions of the same genomic region showing opposite phenotypes. Sotos syndrome is caused by alterations in the dosage of NSD1 on human chromosome 5 by either deletions or mutations, such as microdeletion of $5 \mathrm{q} 35.2 \mathrm{q} 35.3$. In general, patients carrying reciprocal microduplication at $5 \mathrm{q} 35.2 \mathrm{q} 35.3$ present no clinical phenotype or milder phenotype than do patients with microdeletion at the same locus. We report the first case of 5q35.2q35.3 microduplication encompassing NSD1 in a patient from central Brazil. We identified a genomic imbalance corresponding to a de novo $0.45 \mathrm{Mb}$ microduplication at $5 \mathrm{q} 35.2 \mathrm{q} 35.3$ by chromosomal microarray analysis and study of lowcopy repeats. The proband had microduplication in the chromosomal region containing NSD1, which resulted in a Sotos syndrome reversed phenotype, and this duplication was associated with microcephaly, short stature, and developmental delay. Analysis of the genomic structure of the rearranged 5q35.2q35.3 chromosomal region revealed two major low-copy repeat families, which caused the recurrent rearrangements. Chromosomal microarray analysis is a potential tool to identify microrearrangements and guide medical diagnosis, which has to be followed by a non-directive genetic counseling approach to improve the quality of life of the patient.

Key words: NSD1; Microduplication; LCR; Sotos Syndrome; CMA

\section{INTRODUCTION}

Genomic disorders are a group of genetic diseases caused by chromosomal rearrangements such as deletions, duplications, and inversions of unique genomic segments at specific regions. The rearrangements arise by the common mechanism of recurrent non-allelic homologous recombination (NAHR) between low-copy repeats (LCR). (Inoue and Lupski, 2002; Lupski and Stankiewicz, 2005; Franco et al., 2010).

Sotos syndrome (SS) (OMIM117550) is an autosomal dominant genomic disorder caused by microdeletion of region $5 \mathrm{q} 35.2 \mathrm{q} 35.3$, which contains NSD1; in $90 \%$ of the cases, SS involves deletions or mutations (Žilina et al., 2013; Chen et al., 2014; Park et al., 2014). SS is characterized by intellectual disability, facial features with frontal bossing, frontoparietal sparseness of hair, apparent hypertelorism, down-slanted palpebral fissures, pre-and postnatal overgrowth, macrocephaly, and advanced bone age (Türkmen et al., 2003; Dikow et al., 2013; Almuriekhi et al., 2015). The incidence of SS is estimated to be 1:14,000-15,000 live births worldwide (Chen et al., 2014; Park et al., 2014).

NSD1 encodes nuclear receptor SET domain-containing protein 1, a histone methyltransferase (Tatton-Brown et al., 2005). NSD1 regulates the expression of $A P C 2$, which participates in brain development through its regulation of neuronal migration and axon guidance. Besides, NSD1 regulates the expression of many other genes required for the normal development of cardiac, skeletal, and renal tissues (Almuriekhi et al., 2015).

Genetics and Molecular Research 16 (1): gmr16019197 
Patients carrying reciprocal microduplication at $5 \mathrm{q} 35.2 \mathrm{q} 35.3$ have no clinical phenotype or have a milder phenotype than do patients with microdeletion of the same region (Kirchhoff et al., 2007; Weise et al., 2012). According to Orphanet Report Series (2016), the number of published cases of the $5 \mathrm{q} 35$ microduplication worldwide is 14 . Here, we report a rare case of 5q35.2q35.3 microduplication in a patient who was evaluated using chromosomal microarray analysis (CMA) and an analysis of LCRs at a public genetics laboratory of Goiás State, central Brazil.

\section{Case report}

The patient is a 4-year-old boy whose weight is $17 \mathrm{~kg}$ and height is $95 \mathrm{~cm}$. He was born to non-consanguineous parents at 37 weeks of gestation. At birth, his weight was $2.5 \mathrm{~kg}$ and crown-heel length was $45 \mathrm{~cm}$. His mother and father were 25 and 29 years old, respectively, at the time of his birth. He was delivered through a cesarean section procedure.

The patient showed expressive speech and developmental delay, moderate intellectual disability, balanic hypospadias, craniofacial dysmorphisms, pervious foramen ovale without hemodynamic consequences, myopia, low-set ear, hypertelorism, and strabismus. His only elder brother is normal. Family history is unremarkable on both sides.

\section{MATERIAL AND METHODS}

The parents signed the informed consent forms approved by the Ethics Committee on Human Research at Pontifícia Universidade Católica de Goiás (CEP-PUC/GO), under the protocol No. 1721/2011. Cytogenetic studies were performed using peripheral blood samples of the patient and his parents by G-banding at approximately 550 band resolution. Short-term lymphocyte cultures were done for the proband and his parents following standard procedures (Verma and Babu, 1995). Genomic DNA was isolated from the peripheral blood of the proband and his parents using QIAamp ${ }^{\circledR}$ DNA mini kit (Qiagen, Germany). Thereafter, genetic analyses were performed on these samples to establish if the origin of DNA rearrangements was de novo or inherited. Next, 250 ng DNA of each sample was digested with NspI, ligated, PCR amplified and purified, fragmented, biotin-labeled, and hybridized to be used in a GeneChip ${ }^{\mathrm{TM}}$ HD CytoScan Array (Affymetrix, Santa Clara, CA, USA), according to manufacturer instructions. The array, designed specifically for cytogenetic research, included approximately 2,696,550 CNV (copy number variation) markers, 743,304 SNP markers, and >1,953,246 non-polymorphic markers. CEL files obtained by scanning the arrays were analyzed using the Chromosome Analysis Suite (ChAS) software (Affymetrix). Gains and losses that affected a minimum of 50 and 25 markers, respectively, in a $100-\mathrm{kb}$ length were initially considered. For determining the LCR structure of $5 \mathrm{q} 35.2 \mathrm{q} 35.3$, the segmental duplication track of the http://genome.ucsc.edu browser was used. An analysis of the duplicated genomic sequences, including known LCRs, was performed (segmental duplication $>1 \mathrm{~kb}$ of non-repeat masked sequence with over $99 \%$ similarities) by comparing them with the $\sim 3.04-\mathrm{Mb}$ region surrounding the proximal 5q35.2q35.3 locus (chr5:175,085,426-178,129,575).

\section{RESULTS}

G-banded karyotyping at approximately 550 band resolution showed a male karyotype (46, XY). CMA detected one genomic imbalance event in the patient's genome,

Genetics and Molecular Research 16 (1): gmr16019197 
which corresponds to de novo $0.45 \mathrm{Mb}$ microduplication at 5q35.2q35.3 (176,382,009176,832,993) x3 (Figure 1). This region included 12 genes: UIMC1, ZNF346, FGFR4, NSD1, RAB24, PRELID1, MXD3, LMAN2, RGS14, SLC34A1, PFN3, and F12. Among these genes, NSD1 is directly involved with SS. Detailed analyses of the rearranged $5 \mathrm{q} 35.2 \mathrm{q} 35.3$ region revealed that three major LCR families contributed to the complexity of this region. Two 211-kb segments (211A and 211B) flanking the disease locus are directly repeated and have $99.2 \%$ identity. Immediately adjacent and distal to the $211 \mathrm{~A}$ and $211 \mathrm{~B}$ direct repeats, there are two 16-kb segments (16A and 16B) that have 99\% identity. Furthermore, there are two $95-\mathrm{kb}$ segments (95A and 95B) that share $98.1 \%$ identity (Figure 2).

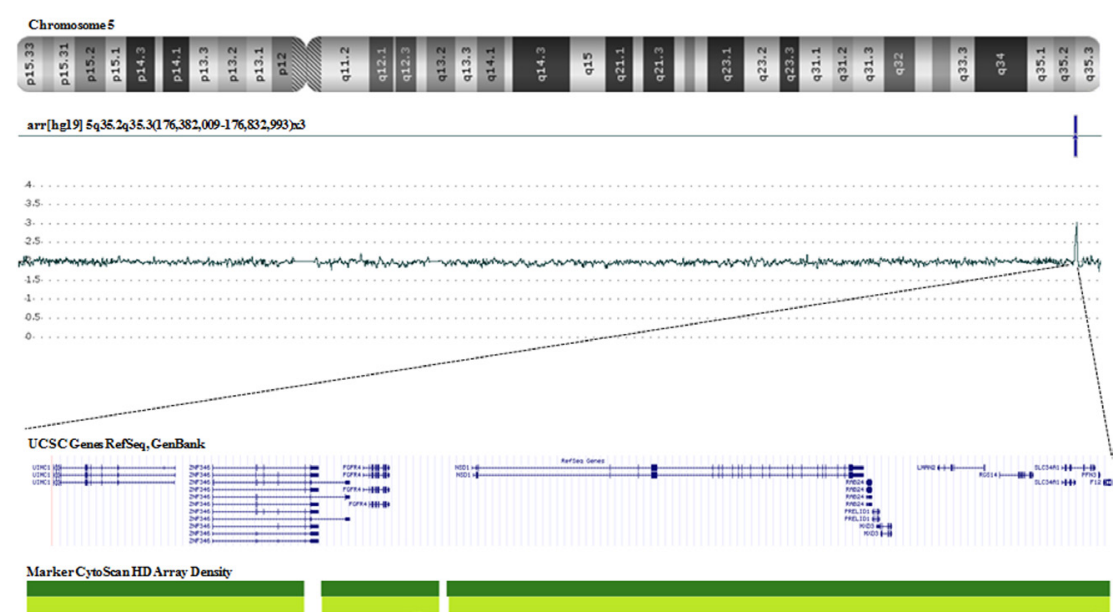

Figure 1. Content of the 5q35.2q35.3 microduplication. CMA showing microduplication of chromosomal segment at $5 \mathrm{q} 35.2 \mathrm{q} 35.3$ from the proband.

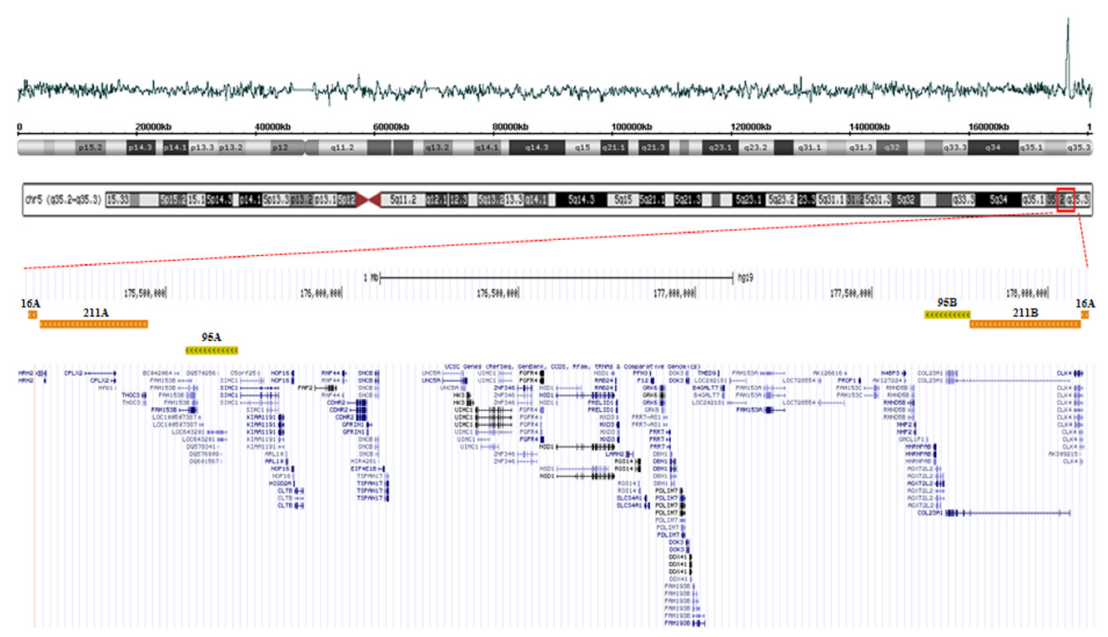

Figure 2. Representation of the three LCR families in the de novo duplicated $0.45 \mathrm{Mb}$ chromosomal region at $5 q 35.2 q 35.3$. There are two LCR families that share 99\% identity (211A and 211B; 16A and 16B) and one LCR family that shares $98 \%$ identity (95A and 95B).

Genetics and Molecular Research 16 (1): gmr16019197 


\section{DISCUSSION}

Here we report the first case of a microduplication associated with the Sotos critical region in Goiás State of central Brazil. The proband exhibits short stature, microcephaly, developmental delay, moderate intellectual disability, craniofacial dysmorphisms, and hypertelorism, which resembles the phenotype associated with microduplication of 5q35.2q35.3 in the region containing NSD1 in SS (Nevado et al., 2014). Our results also suggest that 12 other genes in the microduplicated $5 \mathrm{q} 35.2 \mathrm{q} 35.3$ region could be involved in the pathology of the proband's phenotype.

Variations in human phenotype are generated by chromosomal structural rearrangements, which also contribute towards susceptibility to diseases (Franco at al., 2010). Variations in genomic copy number manifest differently, with duplications and deletions of the same genomic region showing opposite phenotypes (Rosenfeld et al., 2013).

Alteration in NSD1 dosage is responsible for Sotos syndrome, which has an inverted phenotype (Chen et al., 2006; Zhang et al., 2011). However, it is inappropriate to term the phenotype arising from the $5 \mathrm{q} 35$ microduplication as a "reversed SS" as there are other chromosomal imbalances that manifest as short stature and microcephaly, but lack the "reversed facial features" that are observed in patients harboring the duplicated 5q35.2q35.3 chromosomal region (Dikow et al., 2013).

Microduplication occurs via NAHR; when the rearrangement breakpoints flank LCRs, recurrent deletion is followed by reciprocal duplication (Novara et al., 2014). Analysis of the genomic structure of the rearranged $5 \mathrm{q} 35.2 \mathrm{q} 35.3$ chromosomal region revealed two major LCR families. These LCRs are possibly involved in generating the recurrent deletions and reciprocal duplications by NAHR in SS.

This is the first case report of a microduplication event at $5 \mathrm{q} 35.2 \mathrm{q} 35.3$ from central Brazil. Microdeletion in this region occurs with high frequency and is associated with the SS. However, the characterized microduplication has reciprocal rearrangement and the reverse phenotype of microdeletion. We believe that CMA is a potential diagnostic tool that would identify microrearrangements and guide medical diagnosis in the future. The diagnosis has to be complemented by non-directive genetic counseling to improve the quality of life of patients and their family.

\section{Conflicts of interest}

The authors declare no conflict of interest.

\section{ACKNOWLEDGMENTS}

The authors wish to thank Dr. Rinaldo Wellerson Pereira and the Rede ExeGenS for providing scientific suggestions. Research supported by a grant from $\mathrm{CNPq}$ (Conselho Nacional de Desenvolvimento Científico e Tecnológico) [Edital \#031/564465/2010-10] and FAPEG (Fundação de Amparo à Pesquisa do Estado de Goiás) [\#2011.6002.19.1847.1134-03].

\section{REFERENCES}

Almuriekhi M, Shintani T, Fahiminiya S, Fujikawa A, et al. (2015). Loss-of-Function Mutation in APC2 Causes Sotos Syndrome Features. Cell Reports 10: 1585-1598. http://dx.doi.org/10.1016/j.celrep.2015.02.011

Genetics and Molecular Research 16 (1): gmr16019197 
Chen CP, Lin SP, Lin CC, Chen YJ, et al. (2006). Molecular cytogenetic analysis of de novo dup(5)(q35.2q35.3) and review of the literature of pure partial trisomy 5q. Am. J. Med. Genet. A. 140A: 1594-1600.http://dx.doi.org/10.1002/ ajmg.a.31329

Chen CP, Lin CJ, Chern SR, Liu YP, et al. (2014). Prenatal diagnosis and molecular cytogenetic characterization of a 1.07$\mathrm{Mb}$ microdeletion at 5q35.2-q35.3 associated with NSD1 haploinsufficiency and Sotos syndrome. Taiwan. J. Obstet. Gynecol. 53: 583-587.http://dx.doi.org/10.1016/j.tjog.2014.10.002

Dikow N, Maas B, Gaspar H, Kreiss-Nachtsheim M, et al. (2013). The phenotypic spectrum of duplication 5q35.2-q35.3 encompassing NSD1: is it really a reversed Sotos syndrome? Am. J. Med. Genet. A. 161: 2158-2166. http://dx.doi. org/10.1002/ajmg.a.36046

Franco LM, de Ravel T, Graham BH, Frenkel SM, et al. (2010). A syndrome of short stature, microcephaly and speech delay is associated with duplications reciprocal to the common Sotos syndrome deletion. Eur. J. Hum. Genet. 18: 258-261.http://dx.doi.org/10.1038/ejhg.2009.164

Inoue K and Lupski JR (2002). Molecular mechanisms for genomic disorders. Annu. Rev. Genomics Hum. Genet. 3: 199242. http://dx.doi.org/10.1146/annurev.genom.3.032802.120023

Kirchhoff M, Bisgaard AM, Bryndorf T and Gerdes T (2007). MLPA analysis for a panel of syndromes with mental retardation reveals imbalances in $5.8 \%$ of patients with mental retardation and dysmorphic features, including duplications of the Sotos syndrome and Williams-Beuren syndrome regions. Eur. J. Med. Genet. 50: 33-42. http:// dx.doi.org/10.1016/j.ejmg.2006.10.002

Lupski JR and Stankiewicz P (2005). Genomic disorders: molecular mechanisms for rearrangements and conveyed phenotypes. PLoS Genet. 1: e49. http://dx.doi.org/10.1371/journal.pgen.0010049

Nevado J, Mergener R, Palomares-Bralo M, Souza KR, et al. (2014). New microdeletion and microduplication syndromes: A comprehensive review. Genet. Mol. Biol. 37 (Suppl): 210-219. http://dx.doi.org/10.1590/S1415$\underline{47572014000200007}$

Novara F, Stanzial F, Rossi E, Benedicenti F, et al. (2014). Defining the phenotype associated with microduplication reciprocal to Sotos syndrome microdeletion. Am. J. Med. Genet. A. 164: 2084-2090. http://dx.doi.org/10.1002/ ajmg.a.36591

Orphanet Report Series (2016). Prevalence of rare diseases: Bibliographic data - March 2016, Number 1. 1: 60.

Park SH, Lee JE, Sohn YB and Ko JM (2014). First identified Korean family with Sotos syndrome caused by a novel intragenic mutation in NSD1. Ann. Clin. Lab. Sci. 44: 228-231.

Rosenfeld JA, Kim KH, Angle B, Troxell R, et al. (2013). Further Evidence of Contrasting Phenotypes Caused by Reciprocal Deletions and Duplications: Duplication of NSD1 Causes Growth Retardation and Microcephaly. Mol. Syndromol. 3: 247-254.

Tatton-Brown K, Douglas J, Coleman K, Baujat G, et al.; Childhood Overgrowth Collaboration (2005). Genotypephenotype associations in Sotos syndrome: an analysis of 266 individuals with NSD1 aberrations. Am. J. Hum. Genet. 77: 193-204.http://dx.doi.org/10.1086/432082

Türkmen S, Gillessen-Kaesbach G, Meinecke P, Albrecht B, et al. (2003). Mutations in NSD1 are responsible for Sotos syndrome, but are not a frequent finding in other overgrowth phenotypes. Eur. J. Hum. Genet. 11: 858-865. http:// dx.doi.org/10.1038/sj.ejhg.5201050

Verma R and Babu A (1995). Human Chromosomes: Principles and Techniques. McGraw-Hill. Inc., New York.

Weise A, Mrasek K, Klein E, Mulatinho M, et al. (2012). Microdeletion and microduplication syndromes. J. Histochem. Cytochem. 60: 346-358. http://dx.doi.org/10.1369/0022155412440001

Zhang H, Lu X, Beasley J, Mulvihill JJ, et al. (2011). Reversed clinical phenotype due to a microduplication of Sotos syndrome region detected by array CGH: microcephaly, developmental delay and delayed bone age. Am. J. Med. Genet. A. 155: 1374-1378. http://dx.doi.org/10.1002/ajmg.a.33769

Žilina O, Reimand T, Tammur P, Tillmann V, et al. (2013). Patient with dup(5)(q35.2-q35.3) reciprocal to the common Sotos syndrome deletion and review of the literature. Eur. J. Med. Genet. 56: 202-206. http://dx.doi.org/10.1016/j. ejmg.2013.01.008

Genetics and Molecular Research 16 (1): gmr16019197 